Atmos. Chem. Phys., 17, 13721-13729, 2017

https://doi.org/10.5194/acp-17-13721-2017

(C) Author(s) 2017. This work is distributed under

the Creative Commons Attribution 3.0 License.

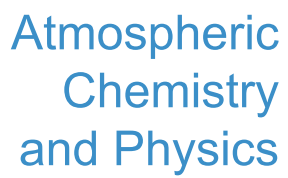

(c) (P)

\title{
Aerosol emissions factors from traditional biomass cookstoves in India: insights from field measurements
}

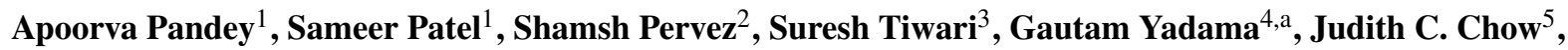 \\ John G. Watson ${ }^{5}$, Pratim Biswas ${ }^{1}$, and Rajan K. Chakrabarty ${ }^{1}$ \\ ${ }^{1}$ Center for Aerosol Science and Engineering, Department of Energy, Environmental and Chemical Engineering, \\ Washington University in St. Louis, St. Louis, MO 63130, USA \\ ${ }^{2}$ School of Studies in Chemistry, Pandit Ravishankar Shukla University, Raipur, Chhattisgarh 492010, India \\ ${ }^{3}$ Indian Institute of Tropical Meteorology, Pune, Maharashtra 411008, India \\ ${ }^{4}$ Brown School of Social Work, Washington University in St. Louis, St. Louis, MO 63130, USA \\ ${ }^{5}$ Division of Atmospheric Sciences, Desert Research Institute, Reno, NV 89512, USA \\ anow at: School of Social Work, Boston College, Boston, MA 02467, USA
}

Correspondence to: Rajan K. Chakrabarty (chakrabarty@wustl.edu)

and Apoorva Pandey (apoorva@wustl.edu)

Received: 29 March 2017 - Discussion started: 23 May 2017

Revised: 25 August 2017 - Accepted: 5 October 2017 - Published: 17 November 2017

\begin{abstract}
Residential solid biomass cookstoves are important sources of aerosol emissions in India. Cookstove emissions rates are largely based on laboratory experiments conducted using the standard water-boiling test, but real-world emissions are often higher owing to different stove designs, fuels, and cooking methods. Constraining mass emissions factors (EFs) for prevalent cookstoves is important because they serve as inputs to bottom-up emissions inventories used to evaluate health and climate impacts. Real-world EFs were measured during winter 2015 for a traditional cookstove (chulha) burning fuel wood, agricultural residue, and dung from different regions of India. Average ( $\pm 95 \%$ confidence interval) EFs for fuel wood, agricultural residue, and dung were (1) $\mathrm{PM}_{2.5}$ mass: 10.5 (7.7-13.4) $\mathrm{g} \mathrm{kg}^{-1}$, $11.1(7.7-15.5) \mathrm{g} \mathrm{kg}^{-1}$, and $22.6(14.9-32.9) \mathrm{g} \mathrm{kg}^{-1}$, respectively; (2) elemental carbon (EC): 0.9 (0.6-1.4) $\mathrm{g} \mathrm{kg}^{-1}, 1.6$ (0.6-3.0) $\mathrm{g} \mathrm{kg}^{-1}$, and $1.0(0.4-2.0) \mathrm{g} \mathrm{kg}^{-1}$, respectively; and (3) organic carbon (OC): $4.9(3.2-7.1) \mathrm{g} \mathrm{kg}^{-1}, 7.0$ (3.512.5) $\mathrm{g} \mathrm{kg}^{-1}$, and $12.9(4.2-15.01) \mathrm{g} \mathrm{kg}^{-1}$, respectively. The mean $( \pm 95 \%$ confidence interval) OC / EC mass ratios were 6.5 (4.5-9.1), 7.6 (4.4-12.2), and 12.7 (6.5-23.3), respectively, with OC and EC quantified by the IMPROVE_A thermal-optical reflectance protocol. These real-world EFs are higher than those from previous laboratory-based measurements. Combustion conditions have larger effects on EFs
\end{abstract}

than the fuel types. We also report the carbon mass fractions of our aerosol samples determined using the thermal-optical reflectance method. The mass fraction profiles are consistent between the three fuel categories but markedly different from those reported in past literature - including the source profiles for wood stove $\mathrm{PM}_{2.5}$ emissions developed as inputs to receptor modeling studies conducted by the Central Pollution Control Board of India. Thermally stable OC (OC3 in the IMPROVE_A protocol) contributed nearly $50 \%$ of the total carbon mass for emissions from all fuels.

\section{Introduction}

The Indian subcontinent is a regional hotspot for anthropogenic emissions (Ramanathan and Carmichael, 2008). Carbonaceous aerosol (black carbon, BC; and organic carbon, OC) in India is linked to surface dimming (Kambezidis et al., 2012), solar warming of the lower atmosphere (Ramanathan et al., 2001, 2007), changing regional monsoon patterns (Chung and Seinfeld, 2005; Menon et al., 2002; Ramanathan et al., 2005), and accelerated melting of Himalayan glaciers (Ramanathan et al., 2007). Particulate matter (PM) emissions - particularly particles with an aerodynamic diameters less than $2.5 \mu \mathrm{m}\left(\mathrm{PM}_{2.5}\right)$ - are also associated with nu- 
merous adverse consequences for human health (Pope et al., 2009; Pope and Dockery, 2006). The Global Burden of Disease study has identified indoor air pollution as the largest risk factor and outdoor air pollution as the seventh largest risk factor for disability-adjusted life years in India (Murray et al., 2013) .

The most recent emissions inventory for India indicated that residential biomass cookstoves are the largest contributors to total annual $\mathrm{PM}_{2.5}$ emissions (Pandey et al., 2014; Sadavarte and Venkataraman, 2014). In 2010, $67 \%$ of Indian households, more than 160 million total, relied primarily on solid fuels for cooking (Census, 2011). Commonly used cooking appliances are mostly mud stoves, with some three-stone-type brick stoves and metal stoves (Kar et al., 2012) that burn fuel wood, agricultural residue, and dried cattle dung. Traditional cookstoves have low combustion efficiencies, resulting in incomplete combustion and high PM emissions (Smith et al., 2000b).

Emissions performance of cookstoves is commonly expressed in terms of mass-based emissions factors $(\mathrm{EFs})$ or mass of pollutant emitted per unit mass of fuel burned. PM emissions rates depend on fuel properties, combustion device, operator behavior, and cooking patterns (Leavey et al., 2015; Sahu et al., 2011; Roden et al., 2009). Cookstove heating efficiencies and EFs are often measured in a laboratory setting using a water boiling test with high- (boiling) and low- (simmering) power phases (Habib et al., 2008; Smith et al., 2000a; MacCarty et al., 2008). These standardized tests are useful for comparing different stove-fuel combinations, but they do not represent real-world stove behaviors found in the field (Roden et al., 2006, 2009; Smith, 2007). Habib et al. (2008) changed the amount of water boiled from 0.5 to $1.5 \mathrm{~kg}$ in the water boiling test, thereby changing the fuel burn rate and burn cycle duration, and they observed a factor of $\sim 2.7$ increase in the $\mathrm{PM}_{2.5} \mathrm{EF}$ and a factor of $\sim 2$ increase in the $\mathrm{OC}$ fraction. A real-world study of Honduran wood-burning cookstoves (Roden et al., 2006) found higher $\mathrm{PM}_{2.5}$ EFs and OC content than those from previous laboratory studies. Roden et al. $(2006,2009)$ found that real-world fire tending and cooking practices (and therefore burn conditions) were important factors determining PM EFs and compositions.

Real-world EFs for commonly used fuel types and cooking technologies in India are needed for accurate bottom-up emissions estimates (Bond et al., 2013, 2004; Pandey et al., 2014). Inventory emissions rates serve as inputs to regional and global atmospheric transport models that predict spatiotemporal profiles of pollutant burdens and associated impacts on climate and human health (Bond et al., 2013; Guttikunda and Calori, 2013; Sadavarte et al., 2016; Schulz et al., 2006). Alternatively, these inventories are used in conjunction with impact metrics such as intake fraction (Grieshop et al., 2011) and global warming potential (Shindell et al., 2012) to evaluate mitigation policies (MHFW, 2015; Sagar et al., 2016). Such measurements identify key parameters to be monitored during laboratory testing and appliance certification.

With the goals above, we measured cookstove emissions characteristics in a rural Indian household. Local meals were prepared with a traditional mud stove (chulha) using biomass fuels collected from different regions of India. Real-time measurements of emitted gas concentrations were conducted and PM filter samples were collected at regular time intervals during each cooking cycle. $\mathrm{PM}_{2.5}$, OC, and EC EFs are reported here as a function of fuel type and combustion phase. Thermal carbon fractions provided by the IMPROVE_A protocol are also examined.

\section{Methods}

Between 19 and 30 December 2015, 30 separate cooking tests were conducted in a rural household on the outskirts of Raipur, a city located in the central Indian state of Chhattisgarh (abbreviated as Chh.). Approximately $77 \%$ of Chhattisgarh households are located in rural areas and rely almost entirely on solid biomass fuels for cooking (Census, 2011). On a national level, fuel wood, agricultural residue, and dung are used as primary cooking fuels by 49,9 , and $8 \%$ of Indian households, respectively (Census, 2011). Accounting for average combustion efficiencies and calorific values of these fuels, annual fuel usage estimates are $250 \mathrm{Mt}$ of fuel wood, $73 \mathrm{Mt}$ of agricultural residue, and $100 \mathrm{Mt}$ of dung (Pandey et al., 2014). For this study, fuel wood was obtained from Uttar Pradesh (U.P.), Rajasthan (Raj.), Andhra Pradesh (A.P.), Bihar, and Punjab, which collectively account for $35 \%$ of the total fuel wood user base in India. All wood fuels were in the form of chunks with typical dimensions of 5-15 cm. Cattle dung (in the form of dung cakes dried in the sun) was collected from U.P. and Bihar, which account for $60 \%$ of the dung use for cooking in India. Agricultural residues from tur crops (a type of woody stalk) and rice straw were procured from a village near the study location. Test fuels were collected and stored in sealed bags and later analyzed for elemental (carbon, oxygen, hydrogen, nitrogen) composition and moisture content. Fuel compositions are compared in Table 1. Per real-world practice, fuel samples were naturally dried in the sun and stored indoors, bringing moisture contents to $<9 \%$. These compositions are consistent with those reported in other tests (Habib et al., 2008; Smith et al., 2000a).

Table 2 describes the fuels used and the foods cooked; replicate tests were made for some of these combinations with at least three for each fuel. Dung (20-50 g) was doused with approximately $10 \mathrm{~mL}$ of kerosene for initial ignition and the test fuel was added after a steady flame was achieved. Additional fuel of the same type was added as needed. A $10 \mathrm{~min}$ period following lighting of the fire is designated as ignition phase. The remainder of the cooking cycle was designated as the flaming phase when a visible flame was present. Com- 
Table 1. Elemental composition and moisture content of the biomass fuels in this study.

\begin{tabular}{lrrrrr}
\hline \multirow{2}{*}{ Fuel } & \multicolumn{3}{c}{ Elemental composition (\%) } & \multirow{2}{*}{ Moisture content (\%) } \\
\cline { 2 - 4 } & Carbon & Hydrogen & Oxygen & Nitrogen & \\
\hline U.P. dung & 33.1 & 4.0 & 30.0 & 1.6 & 7.5 \\
Bihar dung & 41.4 & 5.1 & 33.6 & 2.1 & 8.6 \\
Chh. rice straw & 40.7 & 5.5 & 39.0 & 0.8 & 5.3 \\
Chh. tur stalk & 48.4 & 6.5 & 42.7 & 0.6 & 4.8 \\
Punjab wood & 50.3 & 0.2 & 40.9 & 0.4 & 6.2 \\
Raj. wood & 49.7 & 5.6 & 42.9 & 0.1 & 5.1 \\
U.P. wood & 49.9 & 0.1 & 41.8 & 0.2 & 3.1 \\
A.P. wood & 48.3 & 0.1 & 43.4 & 0.7 & \\
\hline
\end{tabular}

bustion entered the smoldering phase when the flame died down. The U.P. dung and Chh. rice straw could not sustain the flaming phase for more than a few minutes. Dung is typically smoldered for low-power cooking applications, and it is used as kindling material for igniting fuel wood in a typical rural household. The low carbon content of U.P. dung (Table 1) possibly hinders its ability to sustain a flame, more so than Bihar dung. Rice straw has a low material density and high surface-to-volume ratio and therefore tends to burn out very quickly. It also produces large amounts of smoke, making its use as a stand-alone fuel impractical and harmful for the cook's health. To circumvent these limitations, a few experiments established a steady flame using U.P. dung or Chh. rice straw mixed with U.P. wood (approximately $2.5: 1$ ratio of test fuel mass to wood mass).

The test kitchen (Fig. S1 in the Supplement) was on the first floor of the house, separate from all other rooms. A permanently open door was the only entry from an open terrace. A partially covered window was a second ventilation source. The emissions testing system is shown in Fig. 1. The combustion device was a traditional mud chulha; such stoves have poor heat insulation, poor combustion efficiency, and do not allow proper mixing of fuel and air (Smith et al., 2000a; Venkataraman et al., 2010). An eight-armed stainless steel probe (based on Roden et al., 2006) sampled naturally diluted emissions at $\sim 1.2 \mathrm{~m}$ above the top of the stove. Each arm of the probe was $0.5 \mathrm{~m}$ in length, with four uniformly placed holes facing the plume. This probe was connected to three real-time instruments - a Kanomax portable mobility particle sizer (PAMS) (Kulkarni et al., 2016), a TSI SidePak (Zhu et al., 2007), and a Testo 350 gas analyzer (Wang et al., 2012). The PAMS recorded particle size distributions from 10 to $400 \mathrm{~nm}$ mobility diameter. The SidePak provides a light-scattering $(670 \mathrm{~nm})$ surrogate for measured $\mathrm{PM}_{2.5}$ mass that is calibrated with Arizona road dust (O'Shaughnessy and Slagley, 2002). PM concentrations exceeded the top range of these instruments for short periods during the plume monitoring. The Testo 350 gas analyzer was factory-calibrated prior to the experiments for carbon monoxide (CO) and carbon dioxide $\left(\mathrm{CO}_{2}\right)$. Measured concentrations (acquired ev- ery second) were at least 5 times the detection limits of $1 \mathrm{ppm} \mathrm{CO}$ and $0.01 \% \mathrm{CO}_{2}$ by volume. $\mathrm{PM}_{2.5}$ was collected on $47 \mathrm{~mm}$ Teflon-membrane and pre-baked quartz-fiber filters several times during a cooking cycle using MiniVol $\left(5 \mathrm{~L} \mathrm{~min}^{-1}\right.$ ) samplers (Airmetrics model 4.2) with greased impactor inlets located in the plume $\sim 0.9 \mathrm{~m}$ above the stove. Filter sample durations ranged from 0.5 to $4 \mathrm{~min}$, based on the continuous SidePak reports, to prevent filter overloading. Field blanks were collected (minimum sampling duration of $15 \mathrm{~min}$ ) each day before testing. The Teflon filters were weighed before and after sampling to obtain the net mass deposit that was divided by the sample volume (flow rate times duration) to obtain the concentration. The mass of Teflon filter deposits ranged from 50 to $300 \mu \mathrm{g}$. Quartz filters were analyzed using the Interagency Monitoring of Protected Visual Environments-A (IMPROVE_A) thermal-optical reflectance method (Chow et al., 2007b, 2011) to determine $\mathrm{EC}$ and $\mathrm{OC}$ fractions in the sampled particulates. The minimum detection limits of the thermal-optical reflectance analysis are about $9 \mu \mathrm{g}$ for OC and $1 \mu \mathrm{g}$ for EC (Solomon et al., 2014).

Using the carbon mass balance technique, fuel-based EFs were calculated for each filter:

$$
\mathrm{EF}_{i}=\mathrm{CMF}_{\text {fuel }} \frac{C_{i}}{\Delta C_{\mathrm{CO}_{2}}\left(\frac{M_{\mathrm{C}}}{M_{\mathrm{CO}_{2}}}\right)+\Delta C_{\mathrm{CO}}\left(\frac{M_{\mathrm{C}}}{M_{\mathrm{CO}}}\right)},
$$

where $\mathrm{EF}_{i}$ is the $\mathrm{EF}$ of species $i$ in grams emitted per gram of fuel consumed. $\mathrm{CMF}_{\text {fuel }}$ is the carbon mass fraction of the fuel, which ranged from 33 to $50 \%$ for the tested fuels. $C_{i}$ is the concentration of emitter $i$, in this case $\mathrm{PM}_{2.5}$, OC, or $\mathrm{EC}$, in grams per cubic meter, determined for each Teflon and quartz filter. $\Delta C_{\mathrm{CO}_{2}}$ and $\Delta C_{\mathrm{CO}}$ are the concentrations above ambient levels of $\mathrm{CO}_{2}$ and $\mathrm{CO}$ in grams per cubic meter, respectively. $M_{\mathrm{C}}, M_{\mathrm{CO}_{2}}$, and $M_{\mathrm{CO}}$ are the atomic or molecular weights of $\mathrm{C}, \mathrm{CO}_{2}$, and $\mathrm{CO}$ in grams per mole.

Wireless optical particle sensors (details available in Patel et al., 2017) were attached to the MiniVol sampler and the sampling probe during six experiments to check for any significant differences in the particle concentrations measured at the two locations. Measurements where either sensor was 


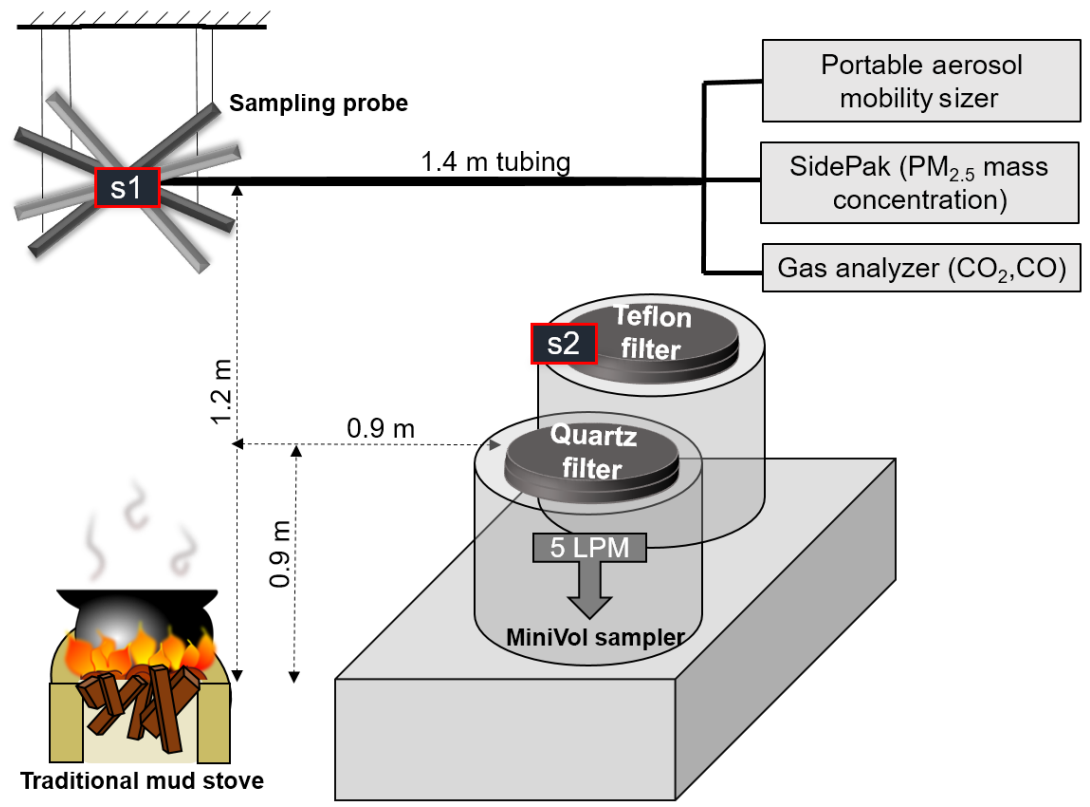

Figure 1. Schematic representation of the experimental setup. S1 and S2 denote the position of the wireless optical sensors.
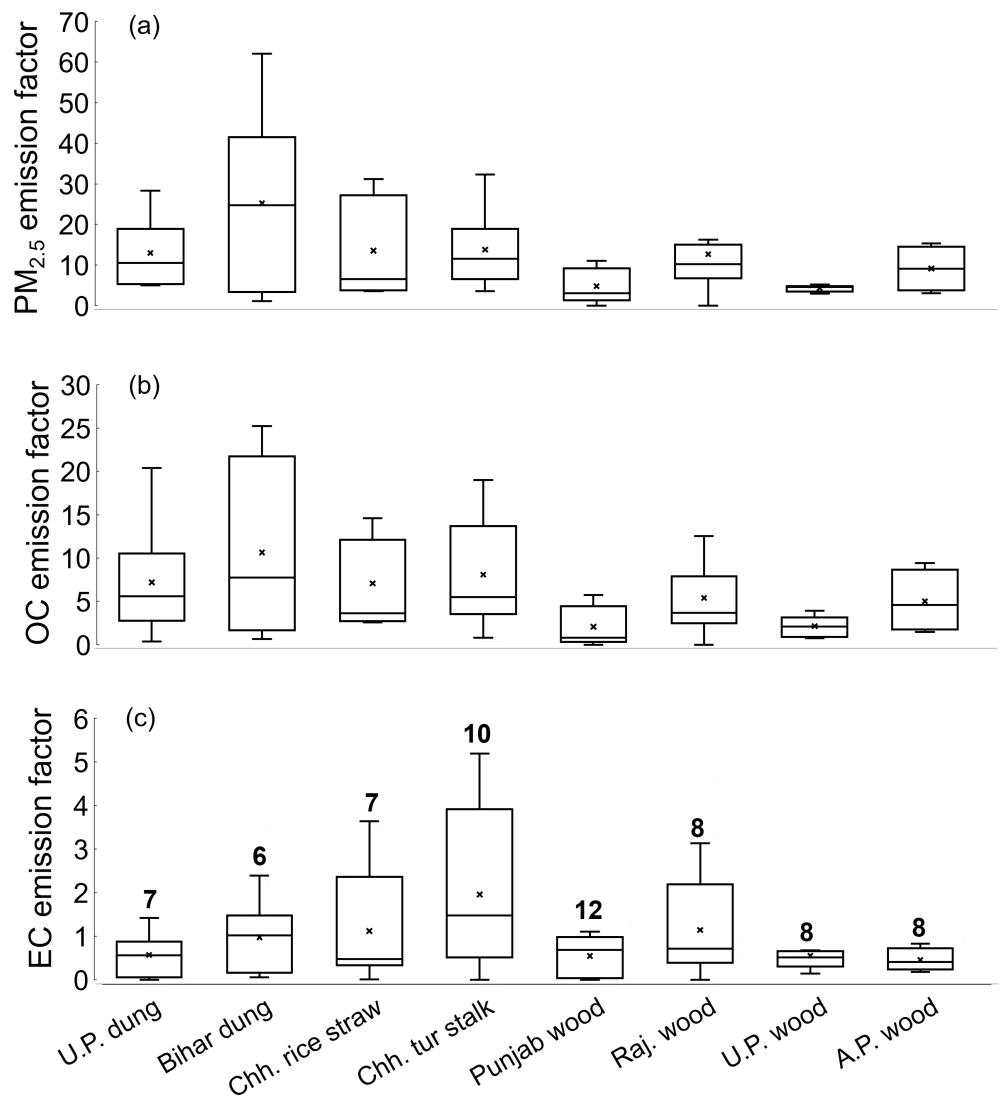

Figure 2. Box plots of (a) $\mathrm{PM}_{2.5}$ emissions factors, (b) OC emissions factors, and (c) EC emissions factors. All emissions factors are expressed in grams of pollutant per kilogram of fuel burnt. Boxes denote lower and upper quartiles; whiskers are 1.5 times the interquartile ranges of the upper and lower quartiles. The numbers above the error bars in panel (c) indicate the number of samples for each fuel. 
Table 2. List of cooking experiments conducted during the 10-day intensive study period. Abbreviations for Indian states: U.P.: Uttar Pradesh; Raj.: Rajasthan; A.P.: Andhra Pradesh; Chh.: Chhattisgarh.

\begin{tabular}{llll}
\hline Day & Primary fuel used & $\begin{array}{l}\text { No. of replicate } \\
\text { experiments }\end{array}$ & Food cooked \\
\hline 1 & Bihar dung & 1 & lentil, rice \\
2 & U.P wood & 2 & rice, vegetables \\
3 & U.P wood & 1 & tea \\
& Raj. wood & 4 & lentils, rice, vegetables \\
4 & U.P. wood & 2 & lentils \\
& A.P. wood & 1 & rice \\
5 & A.P. wood & 2 & rice, vegetables \\
& Bihar dung & 1 & tea \\
6 & Chh. tur stalks & 3 & rice, vegetables, tea \\
7 & U.P. dung* & 3 & vegetables, rice \\
& Bihar dung & 1 & tea \\
8 & Chh. rice straw* & 3 & rice, vegetables \\
& Chh. wood & 1 & tea \\
9 & Raj. wood & 4 & heated water, rice, curry \\
10 & Punjab wood & 1 & milk porridge \\
\hline
\end{tabular}

* Two experiments for each fuel conducted with fuel wood mixed with the test fuel.
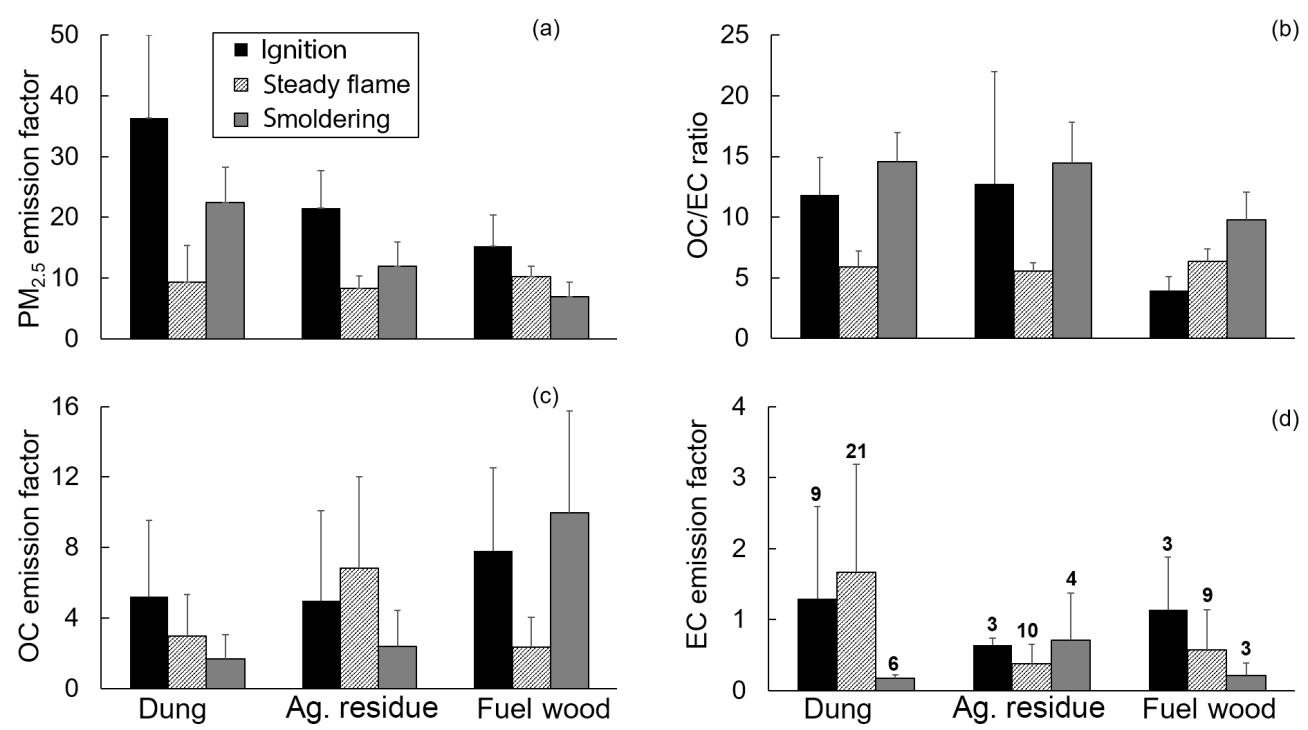

Figure 3. Fuel-wise average values of (a) $\mathrm{PM}_{2.5}$ emissions factors, (b) OC / EC ratios, (c) OC emissions factors, and (d) EC emissions factors, categorized by observed combustion phases. All emissions factors are expressed in grams of pollutant per kilogram of fuel burnt. One-sided error bars are shown to denote 1 standard deviation from the mean. The numbers above the error bars in panel (d) indicate the number of samples for each fuel and combustion phase.

saturated were discarded, and a linear regression analysis was performed on the valid data points. A correction factor of 1.6 was applied based on the regression slope (in the Supplement). Equation (1) assumes that the carbon emitted in $\mathrm{CH}_{4}$, non-methane hydrocarbon, and PM is negligible compared to that in $\mathrm{CO}$ and $\mathrm{CO}_{2}$; it was therefore corrected to account for the small fraction of fuel carbon that gets converted to gaseous volatile OC, assumed as $2.4 \%$ (Habib et al., 2008; Roden et al., 2006).

\section{Results and discussion}

Figure 2 compares EFs for all the test fuels. There are no statistically significant (unpaired Student's $t$ test, $95 \%$ confidence intervals) EF differences for wood fuels from different regions of India. Bihar dung EFs exceeded those for U.P. dung, possibly owing to the addition of wood to sustain flaming. On average, $\mathrm{PM}_{2.5}$ and $\mathrm{OC}$ EFs for dung were higher than those for fuel wood. EFs for dung, rice straw, and tur 

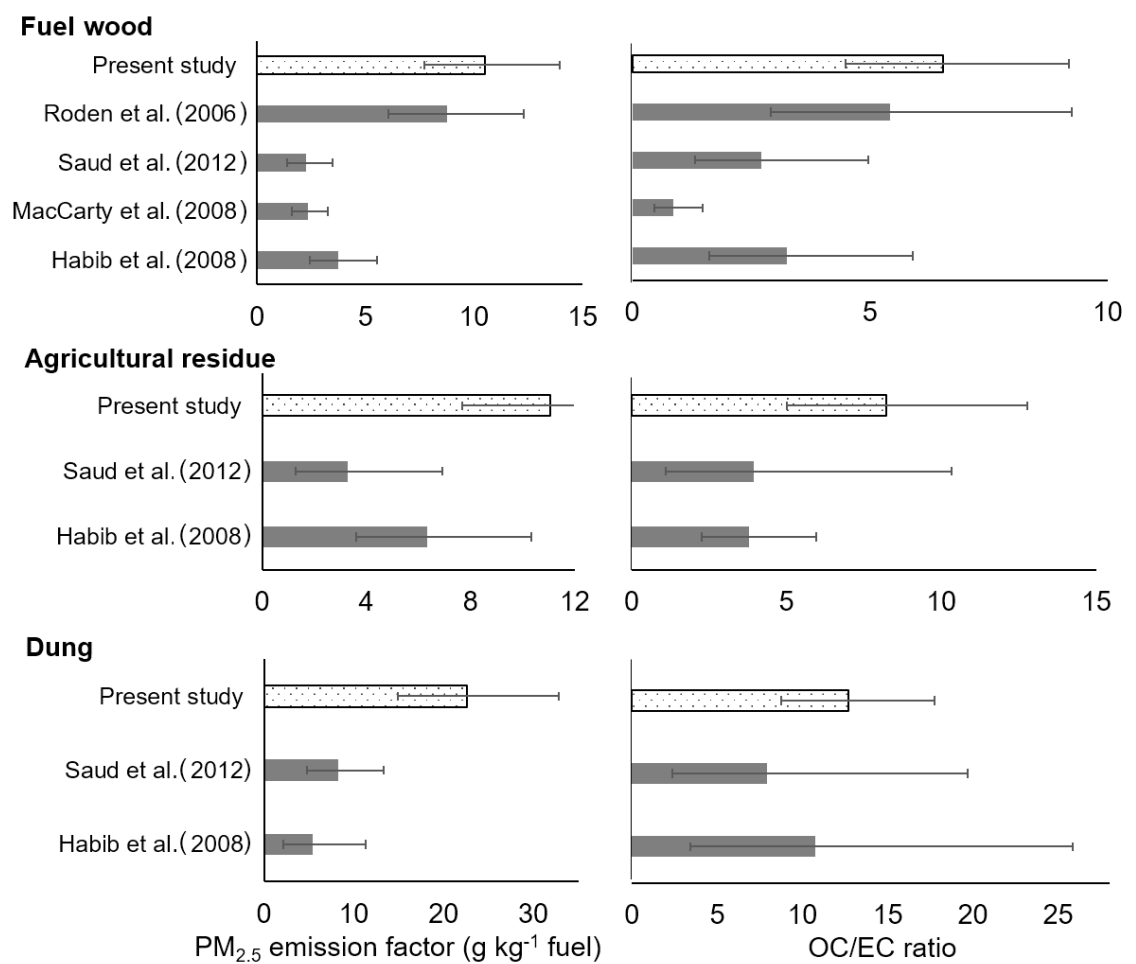

Figure 4. Average $\mathrm{PM}_{2.5}$ emissions factors and $\mathrm{OC} / \mathrm{EC}$ ratios for the three fuel categories in this study, compared with relevant studies. Error bars for values estimated in this study denote $95 \%$ confidence intervals based on standard errors of the means. Error bars for other studies are the bounds reported within those studies.

stalk show a larger spread than corresponding EFs for fuel wood.

Figure 3 compares EFs for the different burning phases. $\mathrm{PM}_{2.5}$ EFs are highest during the ignition phase for all fuels. The OC/EC ratio (Fig. 3b) increases from ignition and flaming to smoldering for all fuels. $\mathrm{CO}$ EFs and modified combustion efficiencies (ratio of $\mathrm{CO}_{2}$ concentration to $\mathrm{CO}+\mathrm{CO}_{2}$ concentration) show no correlation with $\mathrm{PM}_{2.5}$ EFs or OC / EC ratios (in the Supplement). Modified combustion efficiencies exceeded 0.9 - a value associated with flaming (Reid et al., 2005; Zhang et al., 2008) - for nearly $90 \%$ of the test duration, even when no flaming was observed.

Average EFs for the entire burn cycle were calculated as a time-weighted sum of EFs for each phase of combustion. Fuel wood and agricultural residue are used predominantly in flaming conditions to carry out the bulk of cooking operations, resulting in weights of $17 \%$ ignition, $66 \%$ steady flame, and $17 \%$ smoldering. For dung, the weights are $17 \%$ ignition, $17 \%$ flaming, and $66 \%$ smoldering because dung was used for longer low-power operations such as heating water or milk and roasting vegetables. These EFs are compared with other reported EFs in Fig. 4. Average fuel wood $\mathrm{PM}_{2.5}$ EFs and OC / EC ratios in this study are $20 \%$ larger than those reported by Roden et al. (2006) for Honduran cookstoves, but they are $2-8$ times as large as those reported for laboratory studies (Habib et al., 2008; MacCarty et al., 2008; Saud et al., 2012). For agricultural residue and dung, the average EFs and OC / EC ratios are 1.8-4.2 times and 1.3-2.2 times higher, respectively, compared to those reported by Saud et al. (2012) and Habib et al. (2008).

Thermal fractions of total carbon constituted by the IMPROVE_A protocol are compared in Fig. 5. OC1, OC2, OC3, and $\mathrm{OC} 4$ refer to carbon mass that evolves at temperatures of $120,250,450$, and $550^{\circ} \mathrm{C}$, respectively, in the inert helium atmosphere. OP denotes pyrolyzed carbon, which is OC charring in the inert helium carrier. EC1, EC2, and EC3 fractions evolve in a $2 \% \mathrm{O}_{2} / 98 \% \mathrm{He}$ oxidizing atmosphere at 550,700 , and $800{ }^{\circ} \mathrm{C}$, respectively. Figure 5 compares fractions from this study with those reported for controlled biomass (hardwood and softwood) burning reported in Chow et al. (2007a). We also compare our results with a source profile developed for $\mathrm{PM}_{2.5}$ emissions from wood chulhas, as part of source apportionment studies conducted by the Central Pollution Control Board (CPCB) of India (CPCB, 2011). This profile was based on laboratory burns, but details of the test fuel and burn protocol are not known. OC3 was the most abundant fraction, $\sim 50 \%$ of the total carbon mass, while the profiles in literature ranged from 10 to $34 \%$ in the OC 3 fraction. The OC1 fraction for all fuels in this study was uniformly less than $3 \%$, a finding comparable only to the $5 \%$ OC1 reported for softwood but not for the other two profiles. 


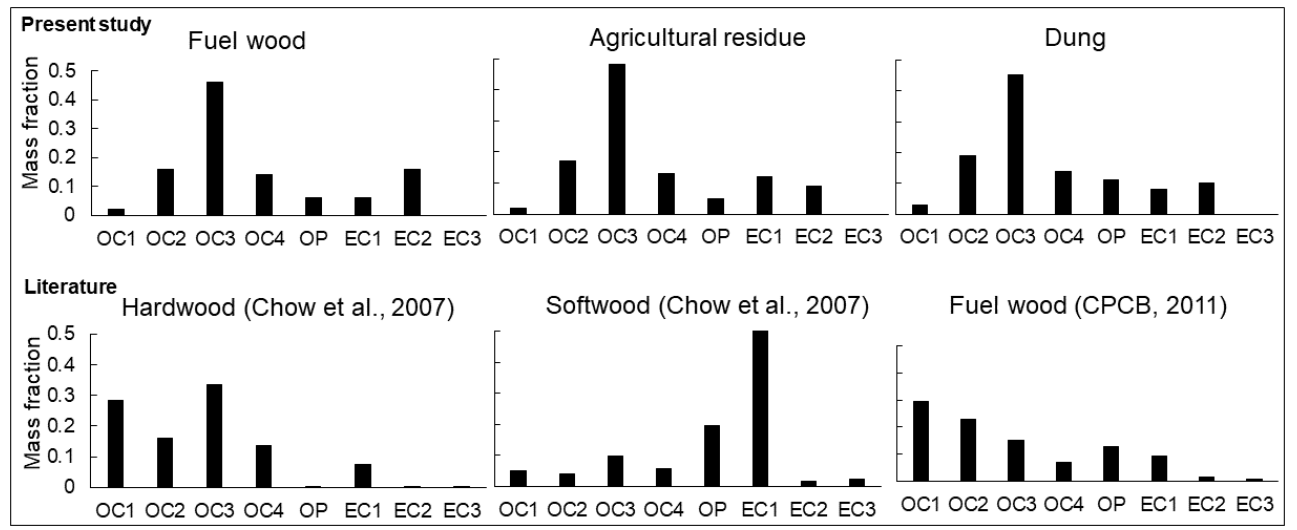

Figure 5. Fraction of total carbon emissions contributed by the IMPROVE_A thermal carbon fractions.

Carbonaceous aerosol source profiles are useful for source apportionment, and they may also have implications for climate and health impact assessments. In a previous study (Pandey et al., 2016), we reported that light-absorbing OC may play a larger role in light absorption by cookstove emissions than that from earlier work on biomass burning in the USA. The difference in constituents of OC emissions from the two sources might contribute to the observed difference in their optical characteristics since thermal stability is known to be inversely related to the light absorption efficiency of organic compounds (Andreae and Gelencsér, 2006; Saleh et al., 2013).

\section{Conclusions}

We estimated $\mathrm{PM}_{2.5}$, OC, and EC mass EFs from real-world combustion of commonly used biomass fuels in India. EFs for fuel wood and dung are more than twice those derived from laboratory tests for similar appliances and fuels. Earlier studies have shown that fuel burn rate (Habib et al., 2008) and fire-tending practices (Roden et al., 2009) affect cookstove emissions; therefore, standardized burn protocols (typically a water boiling test) may not replicate cookstove performance in the field. In a controlled test, variability in wood size could be expected to affect emissions from fuel wood combustion; hence, laboratory studies typically used identical wood chunks. The four wood fuel types in this study were used as chunks in a range of sizes and yielded similar EFs even though these samples were gathered from widely separated parts of India. Overall, the variability in emissions between multiple measurements for the same fuel was larger than or comparable to the differences in average emissions rates for different fuels.

A short period immediately following the ignition phase showed the highest and most variable $\mathrm{PM}_{2.5}$ EFs for all fuels, consistent with previous observations of high emissions from lighting and refueling of stoves (Roden et al., 2009). The use of variable amounts of kerosene and other kindling materials, as required in any burn, may explain the large spread in emissions measurements during ignition. The highest OC / EC ratios were observed during smoldering (no visible flame present), when pyrolysis is the dominant process. The OC3 thermal fraction contributed nearly $50 \%$ of the total carbon mass for emissions from all fuels, indicating that most of the PM emissions are non-evaporative. This could have implications for the climatic impact effect of cookstove emissions, especially since volatility of OC emissions is inversely related to their light absorption efficiency in the near-UV and visible wavelengths (Andreae and Gelencsér, 2006). The thermal fractions found in this study differ from those found in other biomass burning tests, including the source profile used as an input to receptor models of particulate emissions in India (CPCB, 2011). Our findings suggest that combustion conditions may have a larger influence on intrinsic properties of biomass combustion emissions than fuel variability. Connecting aerosol emissions from a given source to their effects on climate and human health requires knowledge of their mass emissions rates and physiochemical properties. The EFs from this study could contribute toward improving evaluations of climate and health impacts of carbonaceous aerosols over India. Further investigation is needed on the relationship between the composition of $\mathrm{OC}$ emissions and their climate and health effects.

Data availability. The emissions factor data set is made available in Table S1 of the Supplement.

The Supplement related to this article is available online at https://doi.org/10.5194/acp-17-13721-2017supplement.

Competing interests. The authors declare that they have no conflict of interest. 
Acknowledgements. This work was partially supported by the National Science Foundation under grant no. AGS1455215, NASA ROSES under grant no. NNX15AI66G, and the International Center for Advanced Renewable Energy and Sustainability (I-CARES) at Washington University in St. Louis. The authors thank Praveen Kumar from Washington University in St Louis for his help with fuel and sample collection. The authors also acknowledge the assistance provided in aerosol sampling and analysis by Madhuri Verma, Rakesh Sahu, and Jeevan Matawale from Pandit Ravishankar Shukla University under the mentorship of Shamsh Pervez.

Edited by: Annele Virtanen

Reviewed by: two anonymous referees

\section{References}

Andreae, M. O. and Gelencsér, A.: Black carbon or brown carbon? The nature of light-absorbing carbonaceous aerosols, Atmos. Chem. Phys., 6, 3131-3148, https://doi.org/10.5194/acp-63131-2006, 2006.

Bond, T. C., Streets, D. G., Yarber, K. F., Nelson, S. M., Woo, J. H., and Klimont, Z.: A technology-based global inventory of black and organic carbon emissions from combustion, J. Geophys. Res.-Atmos., 109, https://doi.org/10.1029/2003JD003697, 2004.

Bond, T. C., Doherty, S. J., Fahey, D., Forster, P., Berntsen, T., DeAngelo, B., Flanner, M., Ghan, S., Kärcher, B., and Koch, D.: Bounding the role of black carbon in the climate system: A scientific assessment, J. Geophys. Res.-Atmos., 118, 5380-5552, 2013.

Census: Houselisting and Housing Census Data, New Delhi, 2011, Office of the Registrar General \& Census Commissioner, India Ministry of Home Affairs, Government of India, available at: http://censusindia.gov.in/2011census/hlo/Houselisting_ Housing_Tables.html (last access: 11 August 2017), 2011.

Chow, J. C., Watson, J. G., Lowenthal, D. H., Chen, L. W. A., Zielinska, B., Mazzoleni, L. R., and Magliano, K. L.: Evaluation of organic markers for chemical mass balance source apportionment at the Fresno Supersite, Atmos. Chem. Phys., 7, 17411754, https://doi.org/10.5194/acp-7-1741-2007, 2007a.

Chow, J. C., Watson, J. G., Chen, L.-W. A., Chang, M. O., Robinson, N. F., Trimble, D., and Kohl, S.: The IMPROVE_A temperature protocol for thermal/optical carbon analysis: maintaining consistency with a long-term database, J. Air Waste Ma., 57, 1014-1023, 2007b.

Chow, J. C., Watson, J. G., Robles, J., Wang, X. L., Chen, L.-W. A., Trimble, D. L., Kohl, S. D., Tropp, R. J., and Fung, K. K.: Quality assurance and quality control for thermal/optical analysis of aerosol samples for organic and elemental carbon, Anal. Bioanal. Chem., 401, 3141-3152, https://doi.org/10.1007/s00216-0115103-3, 2011.

Chung, S. H. and Seinfeld, J. H.: Climate response of direct radiative forcing of anthropogenic black carbon, J. Geophys. Res.Atmos., 110, https://doi.org/10.1029/2004JD005441, 2005.

CPCB: Air quality monitoring, emission inventory and source apportionment study for Indian cities, National Summary Report, Central Pollution Control Board, 2011.
Grieshop, A. P., Marshall, J. D., and Kandlikar, M.: Health and climate benefits of cookstove replacement options, Energ. Policy, 39, 7530-7542, 2011.

Guttikunda, S. K. and Calori, G.: A GIS based emissions inventory at $1 \mathrm{~km} \times 1 \mathrm{~km}$ spatial resolution for air pollution analysis in Delhi, India, Atmos. Environ., 67, 101-111, 2013.

Habib, G., Venkataraman, C., Bond, T. C., and Schauer, J. J.: Chemical, microphysical and optical properties of primary particles from the combustion of biomass fuels, Environ. Sci. Technol., 42, 8829-8834, 2008.

Kambezidis, H., Kaskaoutis, D., Kharol, S. K., Moorthy, K. K., Satheesh, S., Kalapureddy, M., Badarinath, K., Sharma, A. R., and Wild, M.: Multi-decadal variation of the net downward shortwave radiation over south Asia: The solar dimming effect, Atmos. Environ., 50, 360-372, 2012.

Kar, A., Rehman, I. H., Burney, J., Puppala, S. P., Suresh, R., Singh, L., Singh, V. K., Ahmed, T., Ramanathan, N., and Ramanathan, V.: Real-time assessment of black carbon pollution in Indian households due to traditional and improved biomass cookstoves, Environ. Sci. Technol., 46, 2993-3000, 2012.

Kulkarni, P., Qi, C. L., and Fukushima, N.: Development of portable aerosol mobility spectrometer for personal and mobile aerosol measurement, Aerosol Sci. Technol., 50, 1167-1179, https://doi.org/10.1080/02786826.2016.1230662, 2016.

Leavey, A., Londeree, J., Priyadarshini, P., Puppala, J., Schechtman, K. B., Yadama, G., and Biswas, P.: Real-time particulate and CO concentrations from cookstoves in rural households in Udaipur, India, Environ. Sci. Technol., 49, 7423-7431, 2015.

MacCarty, N., Ogle, D., Still, D., Bond, T., and Roden, C.: A laboratory comparison of the global warming impact of five major types of biomass cooking stoves, Energy Sustain. Dev., 12, 5665, 2008.

Menon, S., Hansen, J., Nazarenko, L., and Luo, Y.: Climate effects of black carbon aerosols in China and India, Science, 297, 22502253, 2002.

MHFW, N. D.: Report of the Steering Committee on Air Pollution and Health-Related Issues., Ministry of Health and Family Welfare, Government of India, New Delhi, 2015.

Murray, C. J., Vos, T., Lozano, R., Naghavi, M., Flaxman, A. D., Michaud, C., Ezzati, M., Shibuya, K., Salomon, J. A., and Abdalla, S.: Disability-adjusted life years (DALYs) for 291 diseases and injuries in 21 regions, 1990-2010: a systematic analysis for the Global Burden of Disease Study 2010, The lancet, 380, 21972223, 2013.

O'Shaughnessy, P. T. and Slagley, J. M.: Photometer response determination based on aerosol physical characteristics, AIHA Journal, 63, 578-585, 2002.

Pandey, A., Sadavarte, P., Rao, A. B., and Venkataraman, C.: Trends in multi-pollutant emissions from a technology-linked inventory for India: II. Residential, agricultural and informal industry sectors, Atmos. Environ., 99, 341-352, 2014.

Pandey, A., Pervez, S., and Chakrabarty, R. K.: Filter-based measurements of UV-vis mass absorption cross sections of organic carbon aerosol from residential biomass combustion: Preliminary findings and sources of uncertainty, J. Quant. Spectrosc. Ra., 182, 296-304, 2016.

Patel, S., Li, J., Pandey, A., Pervez, S., Chakrabarty, R. K., and Biswas, P.: Spatio-temporal measurement of indoor particulate matter concentrations using a wireless network of low-cost sen- 
sors in households using solid fuels, Environ. Res., 152, 59-65, 2017.

Pope, C. A. and Dockery, D. W.: Health effects of fine particulate air pollution: lines that connect, J. Air Waste Ma., 56, 709-742, 2006.

Pope, C. A., Burnett, R. T., Krewski, D., Jerrett, M., Shi, Y., Calle, E. E., and Thun, M. J.: Cardiovascular mortality and exposure to airborne fine particulate matter and cigarette smoke, Circulation, 120, 941-948, 2009.

Ramanathan, V., Crutzen, P., Kiehl, J., and Rosenfeld, D.: Aerosols, climate, and the hydrological cycle, Science, 294, 2119-2124, 2001.

Ramanathan, V., Chung, C., Kim, D., Bettge, T., Buja, L., Kiehl, J., Washington, W., Fu, Q., Sikka, D., and Wild, M.: Atmospheric brown clouds: Impacts on South Asian climate and hydrological cycle, P. Natl. Acad. Sci. USA, 102, 5326-5333, 2005.

Ramanathan, V., Ramana, M. V., Roberts, G., Kim, D., Corrigan, C., Chung, C., and Winker, D.: Warming trends in Asia amplified by brown cloud solar absorption, Nature, 448, 575-578, 2007.

Ramanathan, V. and Carmichael, G.: Global and regional climate changes due to black carbon, Nat. Geosci., 1, 221-227, 2008.

Reid, J. S., Koppmann, R., Eck, T. F., and Eleuterio, D. P.: A review of biomass burning emissions part II: intensive physical properties of biomass burning particles, Atmos. Chem. Phys., 5, 799825, https://doi.org/10.5194/acp-5-799-2005, 2005.

Roden, C. A., Bond, T. C., Conway, S., and Pinel, A. B. O.: Emission factors and real-time optical properties of particles emitted from traditional wood burning cookstoves, Environ. Sci. Technol., 40, 6750-6757, 2006.

Roden, C. A., Bond, T. C., Conway, S., Pinel, A. B. O., MacCarty, N., and Still, D.: Laboratory and field investigations of particulate and carbon monoxide emissions from traditional and improved cookstoves, Atmos. Environ., 43, 1170-1181, 2009.

Sadavarte, P. and Venkataraman, C.: Trends in multi-pollutant emissions from a technology-linked inventory for India: I. Industry and transport sectors, Atmos. Environ., 99, 353-364, 2014.

Sadavarte, P., Venkataraman, C., Cherian, R., Patil, N., Madhavan, B., Gupta, T., Kulkarni, S., Carmichael, G., and Adhikary, B.: Seasonal differences in aerosol abundance and radiative forcing in months of contrasting emissions and rainfall over northern South Asia, Atmos. Environ., 125, 512-523, 2016.

Sagar, A., Balakrishnan, K., Guttikunda, S., Roychowdhury, A., and Smith, K. R.: India leads the way: a health-centered strategy for air pollution, Environ. Health Perspect., 124, A116-A117, 2016.

Sahu, M., Peipert, J., Singhal, V., Yadama, G. N., and Biswas, P.: Evaluation of mass and surface area concentration of particle emissions and development of emissions indices for cookstoves in rural India, Environ. Sci. Technol., 45, 2428-2434, 2011.

Saleh, R., Hennigan, C. J., McMeeking, G. R., Chuang, W. K., Robinson, E. S., Coe, H., Donahue, N. M., and Robinson, A. L.: Absorptivity of brown carbon in fresh and photo-chemically aged biomass-burning emissions, Atmos. Chem. Phys., 13, 76837693, https://doi.org/10.5194/acp-13-7683-2013, 2013.
Saud, T., Gautam, R., Mandal, T., Gadi, R., Singh, D., Sharma, S., Dahiya, M., and Saxena, M.: Emission estimates of organic and elemental carbon from household biomass fuel used over the Indo-Gangetic Plain (IGP), India, Atmos. Environ., 61, 212-220, 2012.

Schulz, M., Textor, C., Kinne, S., Balkanski, Y., Bauer, S., Berntsen, T., Berglen, T., Boucher, O., Dentener, F., Guibert, S., Isaksen, I. S. A., Iversen, T., Koch, D., Kirkevåg, A., Liu, X., Montanaro, V., Myhre, G., Penner, J. E., Pitari, G., Reddy, S., Seland, Ø., Stier, P., and Takemura, T.: Radiative forcing by aerosols as derived from the AeroCom present-day and pre-industrial simulations, Atmos. Chem. Phys., 6, 5225-5246, https://doi.org/10.5194/acp6-5225-2006, 2006.

Shindell, D., Kuylenstierna, J. C., Vignati, E., van Dingenen, R., Amann, M., Klimont, Z., Anenberg, S. C., Muller, N., JanssensMaenhout, G., and Raes, F.: Simultaneously mitigating near-term climate change and improving human health and food security, Science, 335, 183-189, 2012.

Smith, K.: You don't get what you expect; you get what you inspect, Energy Sustain. Dev., 11, 3-4, 2007.

Smith, K. R., Uma, R., Kishore, V., Lata, K., Joshi, V., Zhang, J., Rasmussen, R., Khalil, M., and Thorneloe, S.: Greenhouse gases from small-scale combustion devices in developing countries, Phase IIa: Household Stoves in India, US Environmental Protection Agency, Research Triangle Park, NC, 98, 2000a.

Smith, K. R., Uma, R., Kishore, V. V. N., Lata, K., Joshi, V., Zhang, J., Rasmussen, R. A., and Khalil, M. A. K.: Greenhouse gases from small-scale combustion devices in developing countries: Phase IIA, Household stoves in India, US EPA, Washington DC, 89, 2000b.

Solomon, P. A., Crumpler, D., Flanagan, J. B., Jayanty, R., Rickman, E. E., and McDade, C. E.: US National PM $_{2.5}$ chemical speciation monitoring networks-CSN and IMPROVE: description of networks, J. Air Waste Ma., 64, 1410-1438, 2014.

Venkataraman, C., Sagar, A., Habib, G., Lam, N., and Smith, K.: The Indian national initiative for advanced biomass cookstoves: the benefits of clean combustion, Energy Sustain. Dev., 14, 6372,2010

Wang, X. L., Watson, J. G., Chow, J. C., Gronstal, S., and Kohl, S. D.: An efficient multipollutant system for measuring real-world emissions from stationary and mobile sources, Aerosol Air Qual. Res., 12, 145-160, 2012.

Zhang, H., Ye, X., Cheng, T., Chen, J., Yang, X., Wang, L., and Zhang, R.: A laboratory study of agricultural crop residue combustion in China: emission factors and emission inventory, Atmos. Environ., 42, 8432-8441, 2008.

Zhu, K., Zhang, J. F., and Lioy, P. J.: Evaluation and comparison of continuous fine particulate matter monitors for measurement of ambient aerosols, J. Air Waste Manage. Assoc., 57, 1499-1506, 2007. 